Session 2313

\title{
STUDENT USE OF INSTRUCTIONAL TECHNOLOGY IN THE INTRODUCTORY CHEMICAL ENGINEERING COURSE
}

\author{
Amy Michel, Richard M. Felder, Jan Genzer, Hugh Fuller \\ North Carolina State University
}

After two decades of largely unfulfilled promise, computers have finally begun to play a significant role in higher education beyond functioning as high-tech typewriters and calculators. In the chemical engineering curriculum, courses have been able to incorporate increasingly complex and realistic examples through the use of spreadsheets, mathematical and process simulation software, multimedia courseware, and resources available through the World Wide Web.

Well-designed instructional technology can facilitate learning in ways that cannot be achieved in a traditional classroom setting. A good courseware package can provide a high level of both visual and verbal presentation of material, as opposed to the overwhelming verbal content of most lectures. It can also provide customized mentoring, enabling students to take an active role in the learning experience by calling on them to answer questions, solve problems, and explore what-if scenarios through the use of simulations. Perhaps most importantly, it can give the students immediate positive or corrective feedback on their responses to questions or solutions to problems in a completely non-threatening or potentially embarrassing manner.

While the potential of computer-assisted instruction to enhance learning is unarguable, rigorous demonstrations of its true effectiveness are in short supply, and the results of most studies that have been carried out have not been conclusive. For example, a group at Purdue University evaluated the use of computer-simulation experiments in a senior-level chemical engineering course. ${ }^{1}$ They found that the computer-simulated experiments led to better learning for some students, while others got more out of a traditional lab experiment. The authors caution against using instructional technology without evaluating its effectiveness.

The effectiveness of any instructional software for a given student depends on a variety of factors, including the quality of the software, the student's learning style and comfort level with technology, and — perhaps most important—how and how much the student uses the software.

The purpose of this paper is to examine how students in a chemical engineering class used a new instructional software package that came with their textbook and how they evaluated the helpfulness of the different components of the package.

\section{Description of the study}

The introductory chemical engineering course at North Carolina State University (CHE 205 Chemical Process Principles) is normally taken in the first semester of the sophomore year. It covers basic engineering calculations, material and energy balances on non-reactive and reactive chemical processes, equations of state for ideal and non-ideal gases, and elementary phase 
equilibrium calculations. It is a 4-credit course and consists of 3 lecture hours and a 2-hour recitation session every week.

In the Fall 1999 semester, 150 students were enrolled in two sections of CHE 205 taught by different instructors, and used as their textbook Elementary Principles of Chemical Processes by R.M. Felder and R.W. Rousseau. ${ }^{2}$ The text comes bundled with a Windows-based CD-ROM courseware package called Interactive Chemical Process Principles (ICPP) developed by Intellipro, Inc., which consists of (a) interactive instructional tutorials covering the major topics in the text, (b) a user-friendly equation-solving program, (c) a physical-property database, (d) a visual encyclopedia of chemical engineering equipment, and (e) the Index of Learning Styles, a self-scoring instrument that assesses learning style preferences defined by Felder. ${ }^{3}$ With the exception of the tutorials, the tools should be useful throughout the chemical engineering curriculum and thereafter. Information was collected about the students' background in computer applications, the nature and extent of their usage of ICPP during the semester, their performance in the course, and their attitudes about the helpfulness of the different ICPP components.

At the beginning of the semester the students completed a preliminary survey about their experience and comfort level with computer applications, and an in-class tutorial was given showing the students how to install the courseware from the CD. A graduate teaching assistant described the courseware tools during several recitation sessions and held office hours throughout the semester to address any problems specifically related to the courseware. Surveys were administered regarding the students' frequency of use of the courseware components and attitudes regarding their helpfulness.

\section{Interactive Chemical Process Principles}

Instructional tutorials. The first component of Interactive Chemical Process Principles is a series of six instructional tutorials. In each tutorial, the students are presented with information about one or more process systems, and are then asked to answer questions and solve problems related to the processes. The software provides positive or corrective feedback on each response. In several of the tutorials, imbedded simulations allow the students to explore and interpret effects of key variable changes on system responses.

An example of the tutorials is the second one in the series, "Material Balances on Non-reactive Single Unit Processes." The process description is as follows:
A liquid mixture of alcohols contains $35.0 \mathrm{wt} \%$ butanol $(B), 41 \mathrm{wt} \%$ pentanol $(P)$, and the balance hexanol $(H)$. A stream of this mixture flows into a distillation column. The overhead product from the column contains 84 wt\% butanol, 11 $w t \%$ pentanol and the balance hexanol and flows at a rate of $1375 \mathrm{~kg} / \mathrm{h}$. The bottom product stream contains $92 \%$ of the hexanol entering the column.

The tutorial first prompts the student to draw and label a flowchart of the process off-line and subsequently displays a completely labeled flowchart in the next frame. (In other tutorials, the student must construct flowcharts on-line.) The student is then asked to express various 
quantities (such the fractional recovery of a component in a specified stream) in terms of labeled variables, carry out a degree-of-freedom analysis of the process, and write independent equations for the unknown labeled quantities using material balances and process specifications. In the course of this analysis, the student develops four independent equations for the four unknown variables on the chart and is then prompted to solve the equations simultaneously using the equation solver, $E-Z$ Solve, that comes with ICPP. The final section calls on the student to change the initial parameters, see how the changes affect system output variables, interpret observed trends, and determine initial conditions that make the problem specifications unattainable.

E-Z Solve. EZ-Solve is an equation-solving and graphing program that obtains numerical solutions of sets of linear or non-linear algebraic and first-order differential equations. It is highly user-friendly (the equations are typed in as they are written, with $+,-, *, /$, and $\wedge$ denoting the arithmetic operations and ' denoting differentiation) and can be used to solve the equations generated in every chapter-end problem in the text. It is now reasonable for instructors to assign problems that involve relatively complex processes (i.e., many simultaneous equations), knowing that the students can solve them in seconds rather than the minutes or hours it would take them to solve the equations manually. The burden is still on the students to derive the correct set of equations, which is what the course is designed to teach them.

Visual Encyclopedia of Chemical Engineering Equipment. This resource, which was developed by Dr. Susan Montgomery of the University of Michigan, provides photographs, schematics, written descriptions, and in some cases animated videos explaining the operation of most equipment used in the chemical process industry. The equipment items described include heat exchangers, separation process units, chemical reactors, pumps and compressors, and process variable measurement instruments. Instructors can assign students to research specified equipment types or students can access the descriptions when they encounter references to equipment items in problem statements.

Physical property database. The database enables students to look up molecular weights, specific gravities, normal melting and boiling points, latent heats of fusion and vaporization, critical temperatures and pressures, and standard heats of formation and combustion for a large number of species. It also contains specific volumes, internal energies, and enthalpies of saturated and superheated steam and liquid water at any temperature and pressure. Finally, it contains built-in polynomial expressions for heat capacities and an integrating function, so that students can specify a species and an initial and final temperature and get an immediate value of the enthalpy change for the transition between the two temperatures.

Index of Learning Styles. The ILS is a 44-item questionnaire used to assess preferences on four learning style dimensions (active/reflective, sensing/intuitive, visual/verbal, and sequential/global). ${ }^{3}$ After completing the survey the student receives information on his or her learning style preferences and suggestions for using the $\mathrm{CD}$ and studying in general based on the results. 


\section{Students' background in computer applications}

Seventy-four percent of the students reported having their own computers at school. Thirty-three percent of the students surveyed rated themselves as very comfortable with computers, $49 \%$ rated themselves as pretty comfortable, $18 \%$ said they were comfortable enough to learn applications when they have to, and none rated themselves as not comfortable ("Turning on the computer strikes fear in my heart"). Most students were familiar with word processing programs such as Word and Word Perfect (65\%), 21\% had used mathematical software such as MathCAD and Maple, $18 \%$ had used spreadsheets, and only $8 \%$ had ever used an interactive CD-ROM. Some commented that an instructional CD came with their course text but was never used in the course.

\section{Student access to the courseware}

After the semester began, the course instructors discovered that the courseware could not be run directly from the CD but had to be installed on a hard drive. Moreover, it could not be installed on local campus workstations or on the campus network server for security reasons. To use ICPP the students either had to install it on their own PCs or use a classmate's computer. Roughly $15 \%$ of the students in the course were precluded from using the courseware and were accordingly eliminated from the sample database for this study. Arrangements are currently being made to remedy this problem in future semesters.

\section{Courseware Usage}

On one occasion the students were assigned to work through one tutorial and look up several equipment items in the Visual Encyclopedia, but any other usage of the courseware was strictly voluntary. An anonymous survey was administered at the end of the semester to assess the nature and frequency of courseware usage. One hundred two of the 150 students in the course $(68 \%)$ were able to access the software and returned usable surveys. Following are the survey questions regarding frequency of use and the students' responses.

- How often did you use ICPP?
(a) $0 \%$ - frequently
(b) $6 \%$ - regularly
(c) $52 \%$ - a few times
(d) $39 \%-1-2$ times
(e) $3 \%$ - never

- How extensively did you use the instructional tutorials?
(a) $10 \%$ - did not work through any of them
(b) $59 \%$ - worked through 1-2 of them
(c) $25 \%$ - worked through $3-5$ of them
(d) $5 \%$ - worked through all 6 of them once
(e) $1 \%$ - worked through all 6 once and some again 
- How often did you use E-Z Solve?
(a) $2 \%$ - many times in CHE 205 and other courses
(b) 3\% - many times for CHE 205 homework
(c) $28 \%$ - a few times for CHE 205 homework
(d) $49 \%$ - only when the instructional tutorial problems called for it
(e) $18 \%$ - never

- How often did you use the Visual Encyclopedia of Chemical Engineering Equipment?
(a) 4\% - many times in CHE 205 and other courses
(b) $2 \%$ - many times for CHE 205 homework
(c) 39\% - a few times for CHE 205 homework
(d) $37 \%$ - only when the instructional tutorial problems called for it
(e) $18 \%$ - never

- How often did you use the Physical Property Database?
(a) 3\% - many times in CHE 205 and other courses
(b) $6 \%$ - many times for CHE 205 homework
(c) 29\% - a few times for CHE 205 homework
(d) $41 \%$ - only when the instructional tutorial problems called for it
(e) $21 \%$ - never

- How did you use the Index of Learning Styles?
(a) $8 \%$ - never accessed it
(b) $30 \%$ - completed it but sought no additional information about the results
(c) $44 \%$ - completed it and read descriptions of the learning styles
(d) $18 \%$ - completed it, read the descriptions, and sought additional material

\section{Student-Assessed Helpfulness of Courseware}

- The instructional tutorials helped me solve subsequent homework problems.
(a) $11 \%$ - disagree
(b) $47 \%$ - neutral
(c) $22 \%$ - agree
(d) $21 \%$ - did not do them

- The instructional tutorials improved my understanding of course concepts.
(a) $5 \%$ - disagree
(b) $41 \%$ - neutral
(c) $32 \%$ - agree
(d) $22 \%$ - did not do them

- Using E-Z Solve made problem solving easier.
(a) $15 \%$ - disagree
(b) $30 \%$ - neutral
(c) $33 \%$ - agree
(d) $22 \%$ - did not use it

- Referring to the Visual Encyclopedia made problem statements clearer
(a) $3 \%$ - disagree
(b) $46 \%$ - neutral
(c) $21 \%$ - agree
(d) $30 \%$ - did not use it

- Using the Physical Property database made problem solving easier.
(a) $6 \%$ - disagree
(b) $33 \%$ - neutral
(c) $30 \%$ - agree
(d) $30 \%$ - did not use it

- The Index of Learning Styles gave me useful insights into how I learn.
(a) $17 \%$ - disagree
(b) $43 \%$ - neutral
(c) $30 \%$ - agree
(d) $10 \%$ - did not use it 
- Having ICPP available saved me time.
(a) $23 \%$ - disagree
(b) $44 \%$ - neutral
(c) $19 \%$ - agree
(d) $15 \%$ - did not use it

- Having ICPP available helped my performance in the course.
(a) $29 \%$ - disagree
(b) $48 \%$ - neutral
(c) $9 \%$ - agree
(d) $14 \%$ - did not use it

\section{Discussion}

As mentioned previously, the students were asked to use the courseware in only one assignment. The survey results therefore provide a measure of the extent to which the students voluntarily used it.

The results indicate that they did not use it much. Even though the tools had the potential both to enhance their understanding of course methods on which they would be tested and to streamline calculations in the roughly 100 problems assigned over the course of the semester, none of the 102 students returning the survey reported using the courseware "frequently" and only six of them reported doing so "regularly." Half used it "a few times," and $40 \%$ apparently either used it only for the required tutorial or did not use it at all.

Many more students agreed that the individual courseware tools were helpful than disagreed with this statement, but most were neutral or stated that they had not used the tools. A weak correlation was found between the frequency of use of the courseware and its perceived helpfulness in course performance (Pearson coefficient $R=0.33$ ). No correlations worth mentioning were found between frequency of use and perceived helpfulness of the individual tools, probably because so few students used the tools enough to make a difference.

The implication of these results is that providing unfamiliar instructional software in a timeconsuming engineering course and counting on the students to make use of it on their own is not a particularly effective strategy. Students who take the course in the fall of 2000 will be given more practice in the use of the software and the study will be repeated to see if the additional practice leads to greater voluntary use.

\section{Acknowledgment}

This work was performed under the auspices of the N.C. State University Preparing the Professoriate program.

\section{Bibliography}

1. S. White and G. Bodner, "Evaluation of Computer-Simulated Experiments in a Senior-Level Capstone ChE Course," Chem. Engr. Educ. 33 (1), 34-39 (1999).

2. R.M. Felder and R.W. Rousseau, Elementary Principles of Chemical Processes, $3^{\text {rd }}$ ed., John Wiley \& Sons, New York, 2000.

3. R.M. Felder, "Reaching the Second Tier: Learning and Teaching Styles in College Science Education," J. College Science Teaching, 23 (5), 286-290 (1993). 
AMY MICHEL

Amy Michel is currently a doctoral student in the Department of Chemical Engineering at North Carolina State University. She received her B.S. in Chemical Engineering from Ohio Northern University. Her dissertation is in the area of semiconductor processing, and she is also participating in N.C. State's Preparing the Professoriate mentorship program. She expects to complete her degree requirements in 2001.

\section{RICHARD FELDER}

Richard Felder is Hoechst Celanese Professor (Emeritus) of Chemical Engineering at North Carolina State University and Faculty Development Codirector of the NSF-sponsored SUCCEED Coalition. He is co-author of Elementary Principles of Chemical Processes (Wiley, 2000), a Fellow Member of the ASEE, and codirector of the National Effective Teaching Institute.

\section{JAN GENZER}

Jan Genzer is Assistant Professor of Chemical Engineering at North Carolina State University. He received his undergraduate education at the Prague Institute of Chemical Technology, Czech Republic, and his Ph.D. in Materials Science and Engineering from the University of Pennsylvania. His research interests include the behavior of polymers at surfaces and interfaces, polymer thermodynamics, and materials self-assembly.

\section{HUGH FULLER}

Hugh Fuller is Director of Educational Assessment for the North Carolina State University College of Engineering. Prior to taking this position, he was Director of Institutional Research and Director of the N.C. State Academic Skills Program. His current interests include assessing attitudes toward engineering and confidence levels of firstyear engineering students. 